\title{
correspondence
}

\section{Fast reactors will be problematical and expensive}

SIR,-I did not reply at once to Dr Smith's letter (23 August, p630) which criticises my article (26 July, p 270) on fast reactors as I was not sure quite how to reply. It now seems to me that the best way I can deal with the issues he has raised and his list of my supposed errors - elementary, outstanding and otherwise - is to quote other authors who have made similar points, with appropriate references so that any interested readers can check for themselves. So this letter is rather long but the issues are important in view of the continuing discussion in Britain on CFR 1 .

I will start with my four "outstanding errors" in physics. One is the misprint on the Doppler effect. It is remarkable that Dr Smith felt it necessary to refer to this "error" as the full version ${ }^{1}$ of the lecture I gave at a conference in London last year has been available to him at Risley since May. My July article was simply a shortened version of the lecture, but there was no misprint in the full version.

The second "outstanding error" is my statement that a thermal reactor has less than one critical mass. If Dr Smith does not accept me as an authority on this point, perhaps he will accept Hans Bethe (Director, Theoretical Physics Division, Manhattan Project, Los Alamos 1943-46; Professor of Theoretical Physics, Cornell University since 1937; Nobel Prize for Physics 1967). Bethe ${ }^{2}$ states in his testimony in support of nuclear power to the State Legislature of California in 1975: "The most important difference between a fast and a slow neutron reactor is that a fast reactor contains more than one critical mass. (By contrast the material in a light water reactor can never form a critical mass because the concentration of the fissile isotope ${ }^{235} \mathrm{U}$ is very low.)" The point is, of course, that a thermal reactor goes critical only in the presence of a moderator whereas a critical mass of a substance is that mass (at normal density) which goes critical by itself.

The third "outstanding error" is that "thermal reactors are designed to be in their most reactive nuclear configuration". This is indeed a possible design requirement for a thermal reactor, although not for fast reactors, and is sensible design practice for commercial thermal reactors. Compare Fauske's lecture $\mathrm{e}^{3}$ at the International Conference on Containment of FBRs at San Francisco in 1977 where he said "Unlike LWRs LMFBRs can be very sensitive to dimensional changes or relocation of core materials since the intact LMFMR core is not in its most reactive configuration". Farmer's examples (12 April, page 593) are not really relevant - overcooling is not a hazard for electricity-generating PWRs although it may have caused incidents in small submarine reactors.

My fourth "outstanding error" is the re-criticality scenario leading to a coredisruptive accident. A more detailed account of such accidents is given in Wilson's article 4 .

So much for the "outstanding errors". Dr Smith then claims that "these errors are important in that they convey the impression that fast reactors are difficult to control, unsafe and not well understood. On the contrary ... Their safety has been the subject

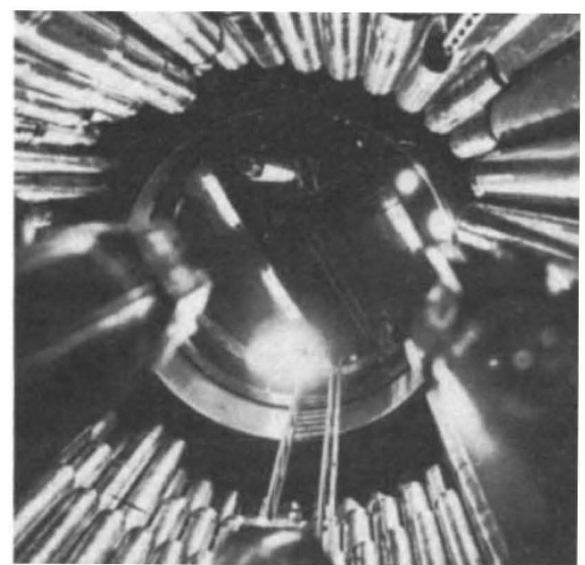

Inside Dounreay's PFR

of intense study for very many years and is well understood." I agree that FBR safety has been studied intensely for many years; unfortunately, however, it will have to be studied intensely for many more. This is in fact the conventional view. At the 1976 meeting in Chicago on Fast Reactor Safety, spokesmen for the UK Nuclear Installations Inspectorate stated " we have indicated the seriousness with which the NII views the possibility of whole-core accidents in a thermal reactor system ... . At the present time however we believe that there are doubts about the adequacy of fault lists, about some of the physical phenomena which might play a part in an accident sequence, about structural materials behaviour, and the performance of protective systems . . . A sound programme of theoretical analysis backed up by suitable model tests is a minimum requirement." My claim that proceeding with a large fast reactor such as CFR1 with a large positive sodium void coefficient will cause even more problems is also shared by others, even by strong proponents of fast reactors such as Professor Bethe $^{6}$. He said at Chicago': "In my opinion, reactor should if possible be so designed that there is no positive void coefficient.'

If we now turn to FBR economics, the argument hinges on two basic points ${ }^{8}$ : the comparative capital costs of FBRs and other reactor systems, for example PWRs; and the future price of uranium. Keck ${ }^{9}$ has demonstrated in the only case study ${ }^{10}$ available that SNR-300 will have cost 5 times as much as an equivalent PWR when it is completed. Dr Smith's comments on SNR-300 are incorrect and the interested reader should consult Keck's massive thesis ${ }^{10}$ where a blowby-blow account is given of how the increased costs were incurred. It may well be that the factor 5 will not be appropriate for the cost of CFR1 compared with a PWR system. Dr Smith claims that an estimate of this facto would be $1.5 \pm 0.5$. I would suggest that it would be wise for the government and electricity board concerned to double this estimate to $3 \pm 1$ in line with the factor of 3 assumed $^{11}$ for the proposed Clinch River breeder reactor in the US. The economis Duncan Burn who has studied the British nuclear industry for many years ${ }^{12}$ made essentially the same point at the London conference last year" ${ }^{13}$ : II do not doubt that following on the long development of the FBR in the UK which has culminated so far in the PFR at Dounreay we can at great cost proceed to construct one or more large $1300 \mathrm{MW}$ prototypes and make a plant which will work and be safe. But it would not necessarily satisfy the economists' criteria.'

Dr Smith then claims that "there is little doubt that lower fuel cycle costs will more than compensate as uranium prices increase due to pressures in the next few decades on limited supplies of uranium ore". My colleagues at the Science Policy Research Unit here are engaged in an SRC sponsored study of fuel cycle costs. Their conclusions on the future price of uranium, in line with authoritative sources in the uranium industry, are that ${ }^{14}$ "In the longer term reserve estimates are rising rapidly, demand growth is being cut back, higher grades of ore will come on stream in the 1980 s and some cost-cutting technical improvements are likely. In the probable absence of an effective cartel, this will provide strong pressure towards a lowering in the long-term real price of uranium for the remainder of this century and possibly even longer."

Dr Smith ends his letter by regretting that my article "gave such an unbalanced view of fast reactor safety". I hope that your readers will prefer the opinion of a distinguished scientist in government service who wrote to me saying "what an excellent and very fair summary".

Yours faithfully,

NORMAN DOMBEY

University of Sussex, Brighton, UK.

1. The Fast Reactor: Need, Cost and Risks? (ed. C Sweet; Macmillan, 1980).

2. Bethe, H., Testimony on the California Nuclear Initiative, 225 (State of California, 1976)

3. Fauske, H.K., Nucl. Eng. Des. 42, 19 (1977).

4. Wilson, R., Rev.mod.Phys. 49, 893 (1977).

5. Hannaford, J. \& Fryer, D.R.H. Proceedings of the International Meeting on Fast Reactor Safety and Related Physics, 1, (American Nuclear Society, 1976) 33. 6. Bethe, H., The Necessity of Fission Power, Scientific American, (January 1976).

7. Bethe, H., Proceedings of the International Meeting on Fast Reactor Safety and Related Physics 1, 341 (American Nuclear 8. Bu, 1976).

9. Bupp, L.C. \& Derian, J.C. Tech. Rev. 76, 26 (1974).

9. Keck, O. The West German-Belgian-Dutch Fast Breeder Programme. A Critical Review of Government Decision of Chicago Center for Policy Studies, 1978). 10. Keck, O. Fast Breeder Reactor Development in West University of Sussex, 1977: British Library Microfilm No D21843/78.

11. Sharefkin, M. The Fast Breeder Decision: An Analysis of Limits and the Limits of Analysis; Joint Economic Committee (US Congress, 19 April 1976).

12. Burn, D. The Political Economy of Nuclear Energy (Institute of Economic Affairs, 1967): Nuclear Power and the Energy Crisis (Macmillan, 1978).

13. Burn, D. Democratic Decision Making; lecture at Conference on Energy Requirements and the Fast Breeder Programme (Polytechnic of the South Bank, London, November 1978).

44. Mackerron, G.S., Surrey, A.J. \& Buckley, C.M. The International Uranium Market, Science Policy Research Uni

\section{Affecting the effect}

SIR, - While affiantly reading page 618 in Nature of 25 October, I found it effascinating how an effroyable use of 'effect' effectively effeebled the meaning. Effacing the 'e' and affixing an ' $a$ ' had an efficacious effect on the affected sentence. The affeebled article's meaning now effulged.

Your affatuated reader,

CSIRO, Epping, New South Wales, Australia. 